\title{
Ethers from esters; from exceptional transformation to synthetic method
}

\author{
Ivana Palej Jakopović,*aa Samra Kapić, ${ }^{a}$ Sulejman Alihodžić, ${ }^{a}$ and Vitomir Šunjićb \\ ${ }^{a}$ Fidelta Ltd., Department of Chemistry, Prilaz baruna Filipovića 29, Zagreb, HR-10000, \\ Croatia \\ ${ }^{b}$ Croatian Academy of Sciences and Arts, Zrinski trg 11, Zagreb, HR-10000, Croatia \\ E-mail:samra.kapic@glpg.com
}

DOI:http://dx.doi.org/10.3998/ark.5550190.p008.960

\begin{abstract}
Most ether-bond forming reactions based on traditional methods or modifications thereof require strongly acidic or basic conditions and often harsh reaction conditions. Reduction of esters to ethers has been regarded as an impracticable method, generally affording alcohols as the principal products. Only recently, original, mostly catalytic methods for reduction of esters to ethers have been reported, which proceed under mild conditions and are compatible with many functional groups present in the substrate ester molecule. These reactions are considered as a valuable alternative to traditional methods, and specific protocols have been reported. An account of the progress in this synthetic methodology is given.
\end{abstract}

Keywords: Reduction, silylation, Lewis acids, esters, ethers lactones, cyclic ethers

\section{Table of Contents}

1. Introduction

2. Overview of Traditional and Less Known Methods

3. Reduction of Esters to Ethers

3.1. Reduction via thiocarbonylation/hydrogenation

3.2. Reduction by complex hydrides

3.3. Reduction by hydrides $\mathrm{x} \mathrm{BF}_{3}$ complexes

3.4. Reductions by silanes and Lewis acids

4. Conclusions

5. Acknowledgment

6. References 


\section{Introduction}

Reactions that form carbon-oxygen bond in ethers belong to the most important transformations in organic chemistry because of the ubiquitous presence of this bond in natural and synthetic compounds. The ether bond is very stable and not easily synthesized; bond energy amounts to $360 \mathrm{~kJ} / \mathrm{mol}$, and is even higher than the single C-C bond $(350 \mathrm{~kJ} / \mathrm{mol}) .{ }^{1}$ It is therefore not surprising that formation of $\mathrm{C}-\mathrm{O}-\mathrm{C}$ bond requires either highly reactive, specifically activated partners or promotion by strong acids and bases at elevated temperatures. Some synthetic methods for ethers have been developed over the decades and have become "named reactions" such as Williamson, Mitsunobu, Mukaiyama and Maruoka synthesis. Traditionally, activation is achieved either by strong acids or bases or more recently by intermediary formation of organometallic species from the reacting esters. All these methods are characterized by the reaction couple nucleophile-electrophile, activated by more or less sophisticated agents, from protons to organometallic species.

A recent mini-review on selective reduction of carboxylic acid derivatives by catalytic hydrosylilation pays attention to the reduction of various derivatives of carboxylic acids. ${ }^{2}$ Selectivity is referred to chemo-selectivity in the presence of other reducible functionalities such as aldehydes, ketones, imines, nitriles, nitro compounds, and multiple C-C bonds. In another mini-review recent developments in the homogeneous hydrogenation of carboxylic acid esters were highlighted. ${ }^{3}$ However only the process which leads to alcohols were discussed, and limited practicability of various sophisticated transition metal complexes revealed. An interesting aspect of selective reduction of esters is their partial reduction to aldehydes, which are known as more reactive species under a variety of reducing conditions. It is general knowledge that aldehydes are reactive intermediates in the reduction of esters to ethers, and are present, if at all, at a very low steady-state concentration. Some recent papers report on progress in a controlled catalytic reduction of esters to aldehydes. ${ }^{4-6}$

In this review methods are presented for reduction of esters to ethers, which have an obvious advantage of using esters as easily available precursors, and are compatible with most sensitive groups, either free or protected. For a long period reduction of esters to ethers was uninvestigated due to the undesired course of this reaction. It is common knowledge that acyclic esters are reduced by complex hydrides to two mole equivalents of alcohols, and lactones to diols, in contrast to reduction of amides to dialkylamines and lactams to cyclic amines. ${ }^{7,8}$ In view of easy synthetic access to esters and lactones, their selective hydrogenation to acylic, non-symmetric esters, and cyclic ethers of various ring-sizes, is of upmost synthetic importance. Recent papers have indeed shown that the mechanism of ester hydrogenation by complex hydrides or silanes can be controlled by Lewis acids and some organometallic species, and preferred formation of ethers has been achieved. Here we report some original methods for completion of the reduction of esters to ethers, their potential to become useful synthetic methods, and we discuss some mechanistic aspects of these reactions. 


\section{Overview of Traditional and Less Known Methods}

Extensive reviews on the traditional ether-forming reactions are available. ${ }^{9,}{ }^{10}$ Here will be presented general comments on the well-known methods.

Alkylation of an alkoxy anion with an alkylhalide/sulfonate under basic conditions, known as the Williamson synthesis, ${ }^{11,12}$ is the most frequently used method for the preparation of ethers. Several $O$-alkylation reactions are variants of Williamson ether synthesis. Most of them are known for a long time, such as alkylation by olefins ${ }^{13}$ by dialkyl phosphates, ${ }^{14}$ by aldehydes, ${ }^{15}$ and by nitro compounds. ${ }^{16}$ The major drawback of this method has been viewed as its unsuitability for base sensitive compounds and the generation of stoichiometric amount of inorganic waste, although this second issue seems to have been overcome by a catalytic etherification developed by Strauss and co-workers. ${ }^{17}$

The Ullmann ether synthesis is a reaction, in which a phenol is coupled to an aryl halide to create a diaryl ether in the presence of a copper compound. ${ }^{18-20}$ Recently, it was found that addition of relatively cheap ligands (diamines, aminoalcohols, diketones, diols) made this reaction catalytic. Progress has been made by combination of mili-scale processing and microwave heating for the $\mathrm{Cu}$-catalyzed Ullmann etherification in chemical synthesis, providing improved catalytic activity. ${ }^{21}$ Also efficient, regio- and chemoselective, reusable, and heterogeneous nano $\mathrm{CuO}$-catalyzed Ullmann type $\mathrm{C}-\mathrm{O} / \mathrm{C}-\mathrm{S}$ cross coupling of aryl halide with phenol/thiophenol has been demonstrated at room temperature. ${ }^{22}$

The Mitsunobu reaction represents a number of substitution reactions of primary and secondary alcohols with various nucleophiles, mediated by a redox system consisting of trialkylor triarylphosphine and dialkyl azidodicarboxylate. ${ }^{23-26}$ This reaction rears different faces when applied in the laboratory and large-scale syntheses. First, it is famous for its scope and power, but also for its separation headaches. Because of so many separation strategies used, the Mitsunobu reaction has been described as "a microcosmos for the new field of strategy level separation". ${ }^{27}$ Despite the poor atom economy, this reaction is popular in organic synthesis at various scales because of its broad scope, stereospecificity and mild reaction conditions.

Dehydrative allylation of primary and secondary alcohols to afford ethers are mediated by various palladium catalysts. ${ }^{28,29}$ There are many variants of inter- and intramolecular allylations of conjugated double bond, where Pd (II) promotes the addition of alcohols to the coordinated $\mathrm{C}=\mathrm{C}$ bond. ${ }^{30,31}$ The palladium catalyzed etherification of allylic alcohols with phenols is promoted by $\mathrm{Ti}(\mathrm{IV})$ isopropoxide, and formation of a transient allyl titanate leading to an $\eta 3$ allylpalladium intermediate is supported by the formation of diallyl and diisopropyl ethers in the absence of a phenol. ${ }^{32}$ Interestingly, we have successfully applied Pd-catalyzed $O$-alkylation of complex macrocyclic alcohols by allyl-tert-butylcarbonate. ${ }^{33,34}$

Diaryl ethers, ${ }^{9,35}$ aryl alkyl ethers ${ }^{36}$ and enol ethers ${ }^{37}$ can be synthesized by means of a palladium-catalyzed Buchwald-Hartwig reaction. Broad application of this metal-catalyzed coupling reaction has mainly been achieved by developing ever more effective ligands for the catalytic complexes, starting from dinitrogen ligands to mono- and bidentate phosphines, and $\pi$ - 
donor alkenes, dba (dibenzylideneacetone) in particular. ${ }^{38}$ Recent progress in this reaction include use of bimetallic heterogeneous catalyst ${ }^{39}$ and heterocyclic carbenes as ligands. ${ }^{40}$

The Mukaiyama method involves an oxido-reductive condensation via alkoxydiphenyldiphosphines, or diphenylphosphinite esters, generated in situ from chlorodiphenylphosphines and alcohols, 2,6-dimethylbenzoquinine and phenols. ${ }^{41,42}$ The reaction proceeds at low temperatures and under neutral conditions to afford alkyl-aryl ethers in high yields. ${ }^{43}$ In 2000 Maruoka and co-workers published a procedure of etherification of benzyl and allylic alcohols by use of the in situ prepared complex $\mathrm{MeAl}\left(\mathrm{NTf}_{2}\right)_{2}$ as a catalyst. ${ }^{44}$ Interestingly, this efficient dimerization of allylic and benzylic alcohols seems not to have been widely introduced since the first report.

Synthesis of ethers from alcohols and carbonyl compounds, aldehydes or ketones, under reductive conditions has been reported by Lemaiere et al. ${ }^{45,46}$ and claimed by Fujii et al. ${ }^{47,48}$ The original method, however, required high pressure of hydrogen, over $40 \mathrm{~atm}$, and a dilute solution of substrate, below $0.2 \mathrm{M}$, leading to many side-products. An improved protocol for reductive coupling of alcohols and carbonyl compounds under a hydrogen atmosphere is reported. ${ }^{48}$ To achieve high yields and conversions, this operationally simple method requires continuous elimination of water, and apparently has only certain limitation in the presence of other reducible groups.

\section{Reduction of Esters to Ethers}

As mentioned in the Introduction, esters are reduced to alcohols accompanied with a split of the $\mathrm{C}-\mathrm{O}$ bond, whereas amides are reduced to amines with the $\mathrm{C}-\mathrm{N}$ bond retained. A mechanistic explanation for different reduction products of these two carboxylic acid derivatives is presented (Scheme 1).
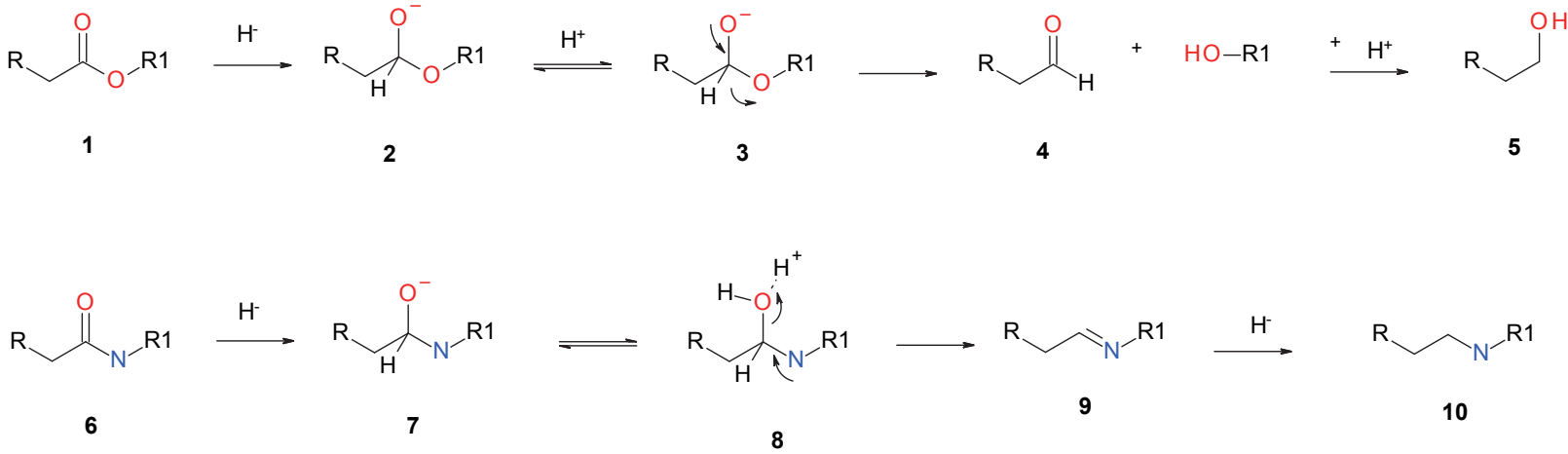

\section{Scheme 1}

Esters are reduced to alcohols since $\mathrm{OR}_{1}$ is a better leaving group than $\mathrm{OH}$; elimination of $\mathrm{R}_{1}-\mathrm{OH}$ preferred, while amides are reduced to sec-amines since elimination of $\mathrm{H}_{2} \mathrm{O}$ is preferred. 
Protonation of the tetrahedral anionic intermediate $\mathbf{2}$, formed on hydride ion addition to ester $\mathbf{1}$, affords hydroxyl and alkoxy group in 3, the later one being a much better leaving group. Intermediary aldehyde $\mathbf{4}$ is then reduced to the second mole of alcohol $\mathbf{6}$. With amides, instead, hydride ion addition and protonation precedes via elimination of water in $\mathbf{8}$ and formation of imine 9 which is then reduced in the second step to the sec-amine 10. From sec-amides an intermediary tert-imonium ion is formed which is easily reduced to tert-amines.

Most of the methods that follow, in particular the catalytic ones, are based on the principle of diminished leaving ability of alkoxy group in favor of the intermediary second, better leaving unit formed from the carbonyl group.

\subsection{Reductions via thiocarbonylation /hydrogenation}

A few years after Lawesson's report on a new method for thionation of esters into thionoesters, ${ }^{49}$ Bradshaw and co-workers developed the method reduction of intermediary thionosters to ethers. ${ }^{50}$ This two-step transformation of esters to ethers is outlined below (Scheme 2).

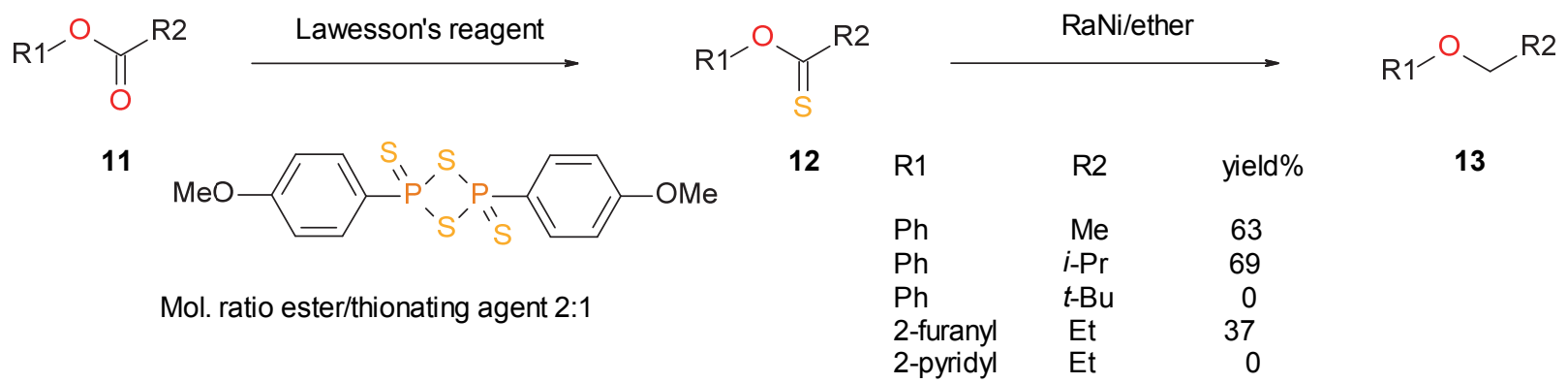

\section{Scheme 2}

Thionating agent 14 is easily available from $\mathrm{P}_{2} \mathrm{~S}_{5}$ and anisole, but thionation of esters in xylene is completed at reflux temperature over a longer period of time. The later conditions limit application of this method to thermally stable esters. In the next step reduction is completed in a few minutes using $\mathrm{RaNi} / \mathrm{H}_{2}$ in a shaker at $-15{ }^{\circ} \mathrm{C}$.
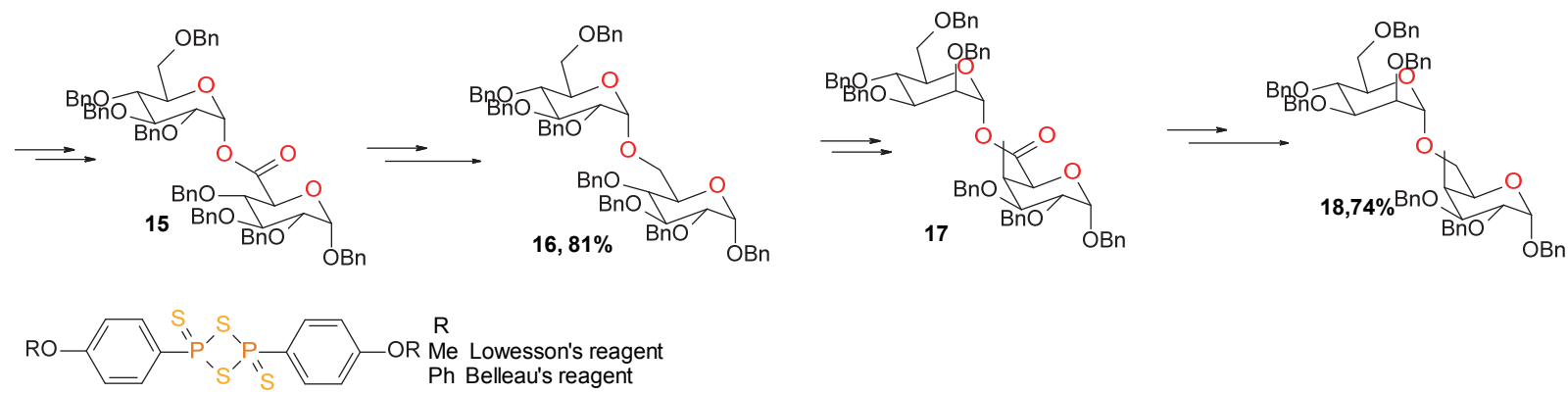

14

Scheme 3 
This method has been used in preparation of disaccharides from the corresponding acetalesters, bound at 1, 6-position by an ether bond (Scheme 3). ${ }^{51}$

It was observed that Lawesson's reagent $(\mathbf{1 4}, \mathrm{R}=\mathrm{Me})$ reacts at elevated temperatures, due to its low solubility in most organic solvents at low temperatures, giving many side-products. Its more soluble analogue, $\mathrm{X}(\mathrm{R}=\mathrm{Ph})$, named Belleauove's reagent, can be used at low temperatures in benzene, chloroform, and DME. On hydrogenation of intermediary thionosters, 1, 6-ethers were obtained in $70-85 \%$ yield.

It is interesting that Belleauove's reagent $(14, \mathrm{R}=\mathrm{Ph})$ and some of its congeners proved particularly effective in preparation of thiolactones from lactones, and then, in turn, in preparation of cyclic ethers and their $\alpha$-alkylated analogs (Scheme 4). ${ }^{52}$

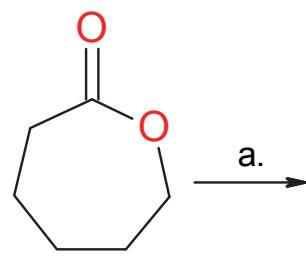

19

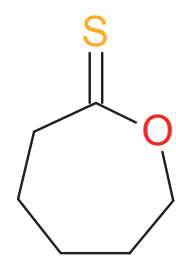

20

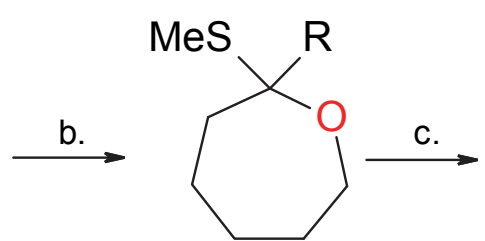

21

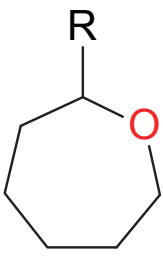

22
Entry
nucleophile (RM)
Addition product
(21) yield (\%)
Reduction product (22) yield\%
$1 \quad$ MeLi
2
PhLi
$\mathrm{R}=\mathrm{Me}$
$\mathrm{R}=\mathrm{Ph}$
3
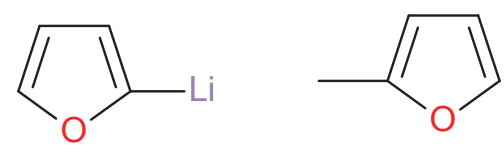
83
86
$\mathrm{R}=\mathrm{Me}$
$\mathrm{R}=\mathrm{Me}$
85

86
92

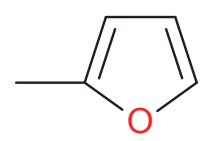
97

92
86

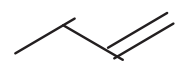
85

Reaction conditions: a. Belleau's reagent, toluene, reflux, $1 \mathrm{~h}$; b. RM/Mel, THF, $-78^{\circ} \mathrm{C}$;

c. $\mathrm{Ph}_{3} \mathrm{SnH}, \mathrm{AIBN}$, toluene, reflux, 20-25 min.

\section{Scheme 4}

Intermediary thionolactones $\mathbf{2 0}$ are quenched in a Grignard-type reaction by organometallic nucleophiles and MeI affording alkylated thioacetals. Reductive desulfurization by triphenyltin hydride $\left(\mathrm{Ph}_{3} \mathrm{SnH}\right)$ affords $\alpha$-alkylated cyclic ethers 22 . This method has been used in preparation of the key building blocks in the total synthesis of brevetoxine and lautasine. ${ }^{52}$

\subsection{Reduction by complex hydrides}

An early reported two-step method of reduction of lactones to cyclic ethers uses DIBAL in combination with $\mathrm{Et}_{3} \mathrm{SiH} / \mathrm{BF}_{3} \cdot \mathrm{Et}_{2} \mathrm{O}$ complex (Scheme 5). ${ }^{53}$ 


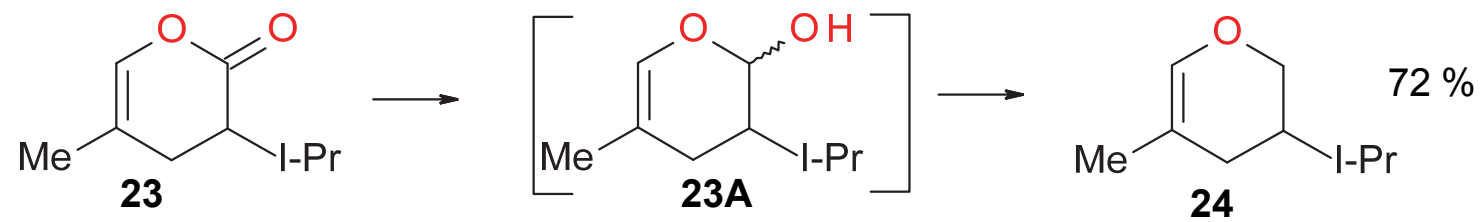

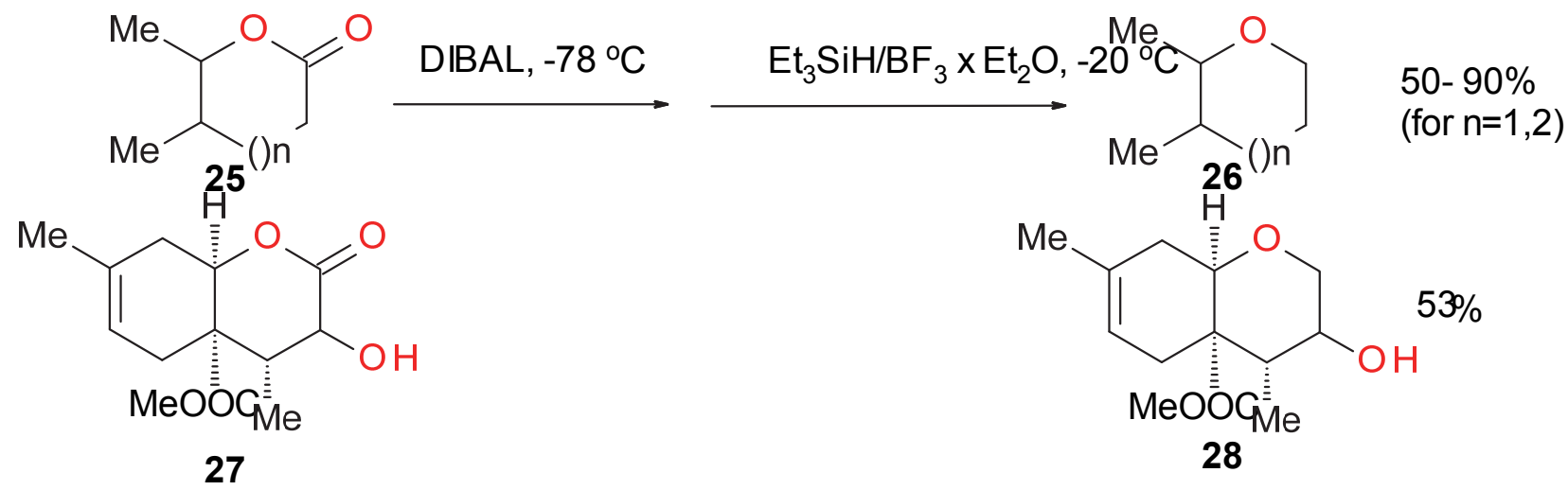

\section{Scheme 5}

This reaction can be stopped under controlled conditions at the level of the cyclic lactole (hemiacetal), which is an intermediate. Thus, intermediary lactol $\mathbf{3 0}$ was isolated in quantitative yield and reduced to 31 by $\mathrm{Et}_{3} \mathrm{SiH} / \mathrm{BF}_{3} . \mathrm{Et}_{2} \mathrm{O}$ in $\mathrm{DCM}$ at $-20{ }^{\circ} \mathrm{C}$, (Scheme 6). On the contrary, the allylic $\mathrm{OH}$ group in $\mathbf{2 9}$ cannot be hydrogenolized by this complex reagent (Scheme 6).<smiles>CC1=CC(O)CC(C)(C)C1</smiles>

no reaction!

29

$\mathrm{Et}_{3} \mathrm{SiH}$ in $\mathrm{DCM} / \mathrm{BF}_{3} \times \mathrm{Et}_{2} \mathrm{O},-20^{\circ} \mathrm{C}$<smiles>CC1=CC(O)OC(C)(C)C1</smiles>

30<smiles>CC1=CCOC(C)(C)C1</smiles>

complete conversion!

\section{Scheme 6}

31 


\subsection{Reduction by hydride $\mathrm{X} \mathrm{BF}_{3}$ complexes}

There is only one report on the reduction of esters to ethers by $\mathrm{LiAlH}_{4}-\mathrm{AlCl}_{3}$ reagent 54. The authors observed that the molar ratio $\mathrm{LiAlH}_{4} / \mathrm{AlCl}_{3}$ was highly important in determining the yield of the ether. However, the yields of ethers were low (7-15\%), and this reagent has not found much application.

Reduction of esters to ethers by the complex $\mathrm{LiAlH}_{4} / \mathrm{BF}_{3}$. Et $\mathrm{H}_{2} \mathrm{O}$ was first described by Pettit et al. ${ }^{55,56}$ During hydrogenation of $3 \beta$-acetoxy derivative of $5 \alpha$-cholestane $\mathbf{3 2}$ the authors observed formation of ether $\mathbf{3 3}$ (Scheme 7).

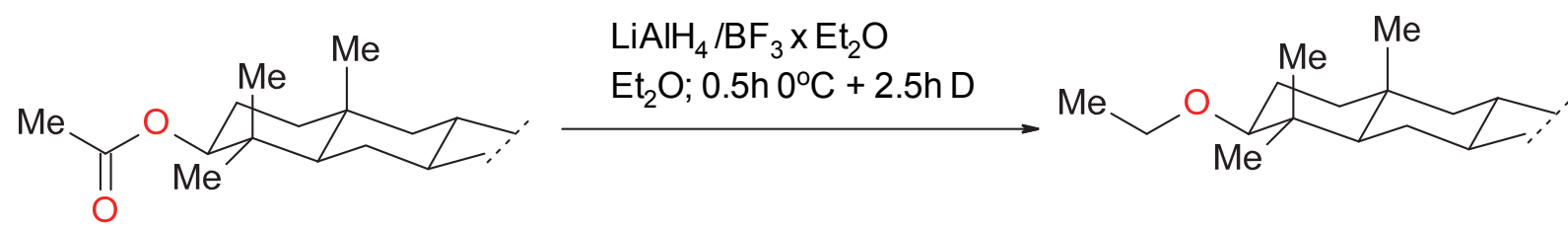

32

33

\section{Scheme 7}

Soon after the authors observed that this reduction is not specific for the acetoxy group, and completed reduction of esters 34 to ethers 35, whereby the complex $\mathrm{NaBH}_{4} / \mathrm{BF}_{3}$. $\mathrm{Et}_{2} \mathrm{O}$ proved equally useful (Scheme 8). ${ }^{57}$

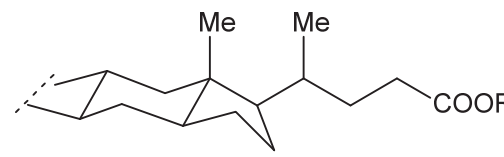

34

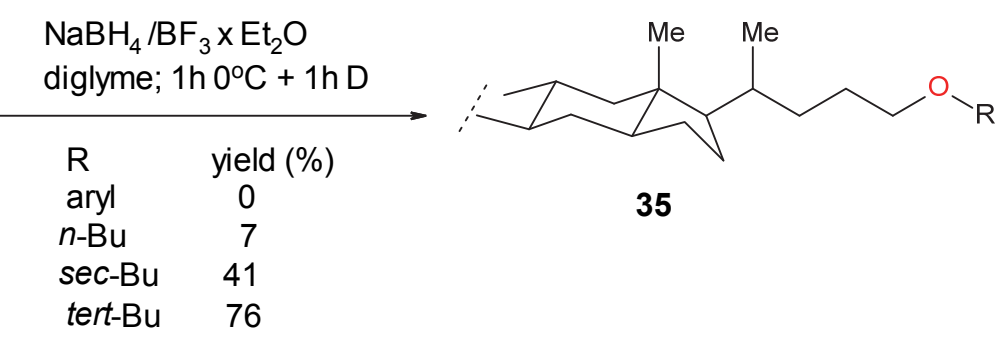

\section{Scheme 8}

Arylesters did not give ethers, and the yield for alkyl esters varied with the structure of the alcohol unit.

The same reducing complex proved less effective in reduction of lactones $\mathbf{3 6}$ to ethers $\mathbf{3 8}$; lactone $36(\mathrm{R}=\mathrm{Me})$ afforded a mixture of lactone $37(44 \%)$ and diol (42\%), while less sterically crowded lactones $(\mathrm{R}=\mathrm{H})$ afforded diol as the only product, (Scheme 9$).{ }^{58,59}$ 


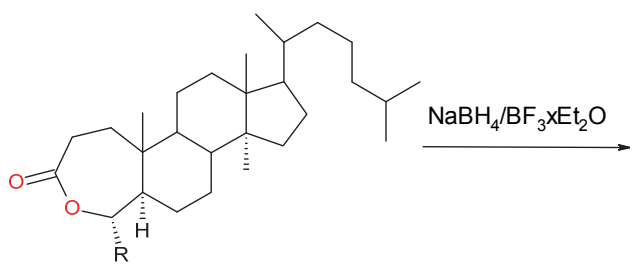

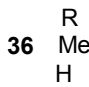

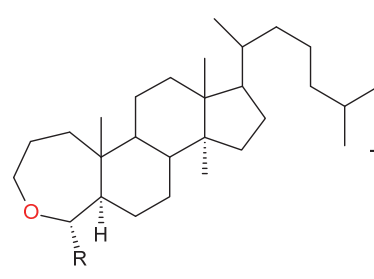

$37 \quad \mathrm{R}$

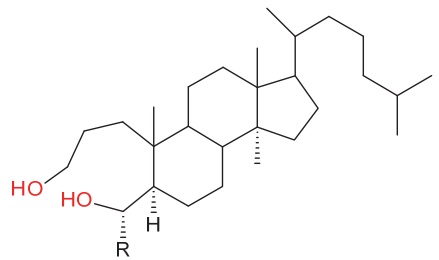

$38 \quad \begin{array}{ll}\mathrm{R} \\ \mathrm{Me} \\ \mathrm{H}\end{array}$

\section{Scheme 9}

This example has for the first time shown beneficial effect of perturbation by the neighboring group in the alcohol unit on reduction directed to ethers. Another interesting example represents reduction of sterically crowded ester 39, which under conditions shown in the Scheme give in $70-80 \%$ yield the neopentyl ether $\mathbf{4 0}$, which proved unavailable by Williamson ether synthesis (Scheme 10). ${ }^{58}$

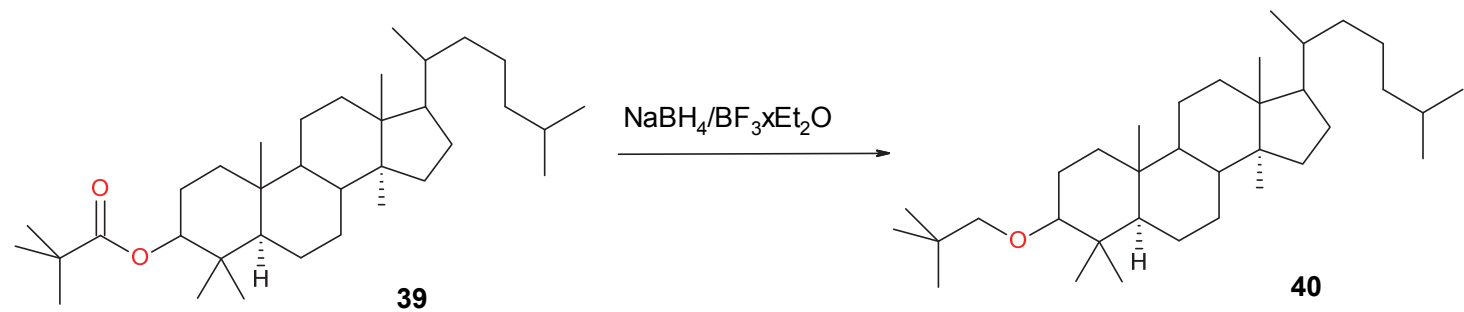

\section{Scheme 10}

Conformationally stable $\delta$-lactones $\mathbf{4 0 , 4 1}$ were reduced to tetrahydrofuran derivatives $\mathbf{4 2 , 4 3}$ in $75 \%$ and $44 \%$ yield, respectively (Scheme 11 ). ${ }^{58}$

Progress in this approach has been achieved by Morra and Pagenkopf, who prepared strong Lewis acids $\mathrm{BF}_{2} \mathrm{OTf} . \mathrm{OEt}_{2}{ }^{60}$ It is well known that coordination of Lewis acids to the carbonyl group plays an important role in a number of reactions, such as ene-ractions, ${ }^{61}$ addition of silanes and stananes to aldehydes and conjugated enones, ${ }^{62}$ Diels-Alder reactions, ${ }^{63}$ and aldol reactions; ${ }^{64}$ The authors concluded the coordinating ability of the Lewis acid to the carbonyl oxygen can orient reduction of esters to ethers. This effect of Lewis acids is outlined in the Scheme 12. 


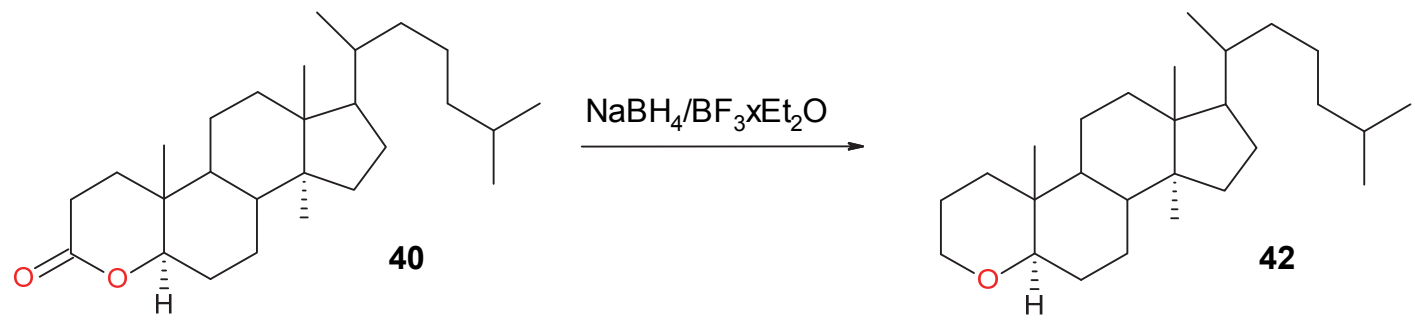<smiles>CC12CCC3C(CC[C@@H]4C(C)(C)C(O)CCC34C)[C@@H]1CCC(=O)O2</smiles><smiles>CCOC(C)C(C)C(C)C</smiles>

\section{Scheme 11}

a)

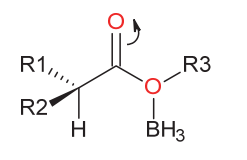

AND Enantiomer

b)<smiles>[R3]OC(=O)C([R2])([R2])[18OH]</smiles>

AND Enantiomer

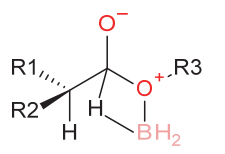

AND Enantiomer<smiles>[R9]OC(=O)C([R2])[R2]</smiles>

$\mathrm{R} 1, \mathrm{R} 2 \mathrm{CH}-\mathrm{CH}_{2} \mathrm{OH}$
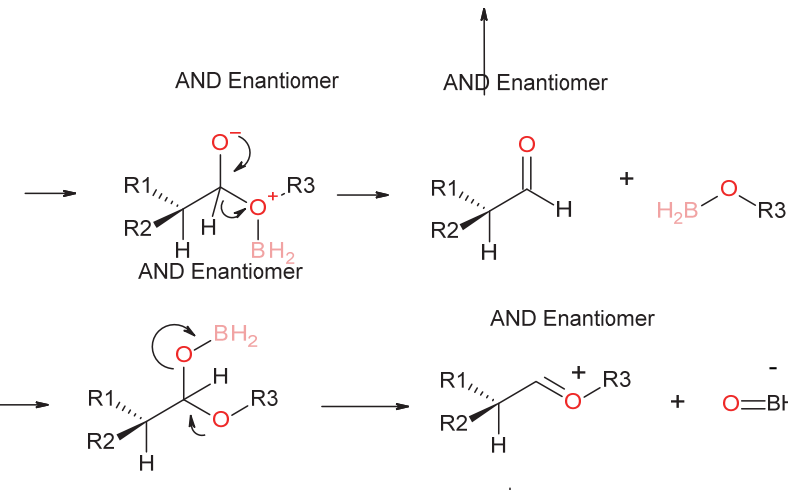

AND Enantiomer

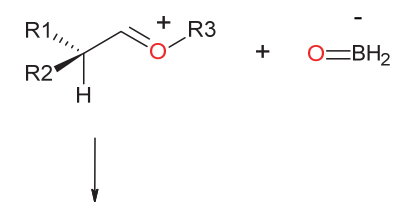

$\mathrm{R} 1, \mathrm{R} 2 \mathrm{CH}-\mathrm{CH}_{2} \mathrm{O}-\mathrm{R} 3$

\section{Scheme 12}

Whereas path (a) leads to formation of alcohols, on the path (b) the split of the C-O bond is precluded and ethers are formed. Along the route (a) in the first step borane is coordinated to the $\mathrm{sp}^{3} \mathrm{O}$-atom, followed by the transfer of the hydride ion to the carbonyl $\mathrm{C}$-atom, elimination of alkoxyborane accompanied by intermediary formation of aldehyde, which in the fast step is reduced to alcohol. On the route (b) borane is in the first step coordinated to carbonyl $\operatorname{sp}^{2} O$ atom, then on transfer of hydride ion the best leaving group became oxoborane. In the last and fast step oxonium ion is reduced to ether. It is assumed that steric strain driven by the substituents on the $\mathrm{R}_{3}$ group precludes formation of an intermediary complex on the route (a) and 
favors the complex on the route (b). Along both paths in the last step the hydride ion is transferred, affording two molar equivalents of alcohol in the first case and one molar equivalent of ether in the second one.

Another presentation of the mechanistic difference in reduction in the presence of protons and Lewis acids is given in the Scheme 13. Direction of reduction to ethers can be controlled by coordination of the strong Lewis acid to the $O$-atom of the carbonyl group.

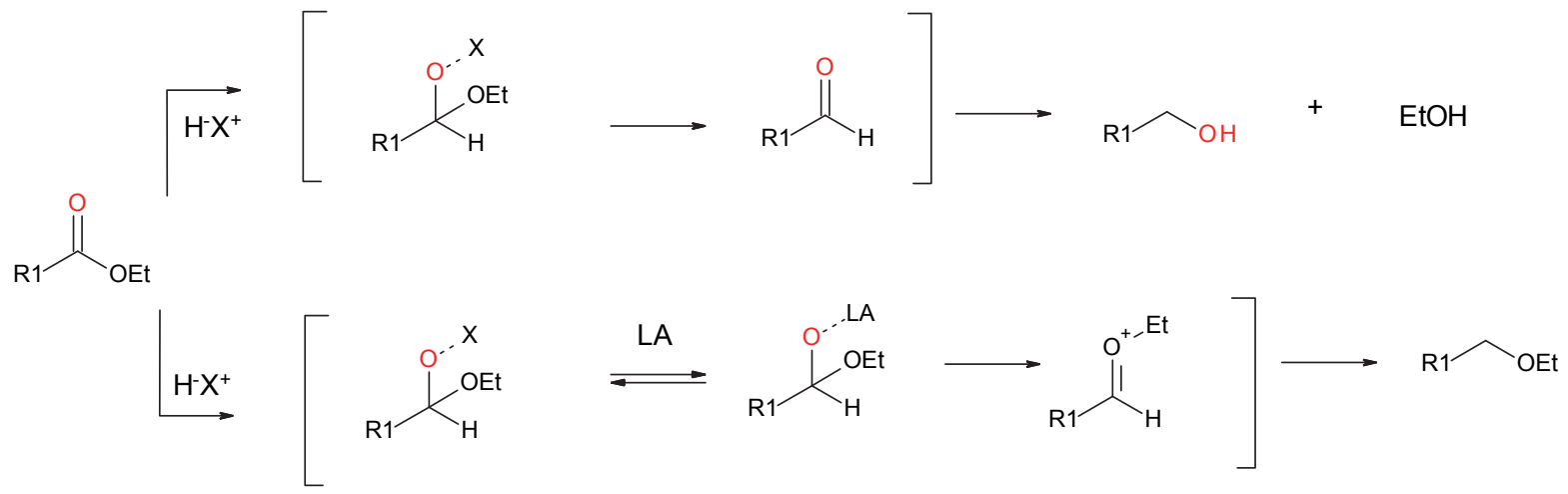

\section{Scheme 13}

A characteristic of the route (b) is transformation of the carbonyl $O$-atom on coordination into the best nucleophilic group, and parallel formation of an alkyl-oxonium ion, which is hydrogenated in the last step. This mechanism indicates that strong Lewis acids can preclude collapse of the tetrahedral intermediate, as in the route (a), and reorient the reaction towards elimination of the complex bearing the former carbonyl $O$-atom.

In order to demonstrate stability of the Lewis acids $\mathrm{BF}_{3} \cdot \mathrm{Et}_{2} \mathrm{O}(\mathrm{X}=\mathrm{Ms}$, $\mathrm{Tf})$ the authors have determined equilibrium constants for the routes (a) and (b) in the Scheme 14. Both equilibria were achieved in few minutes at ambient temperature. ${ }^{60}$

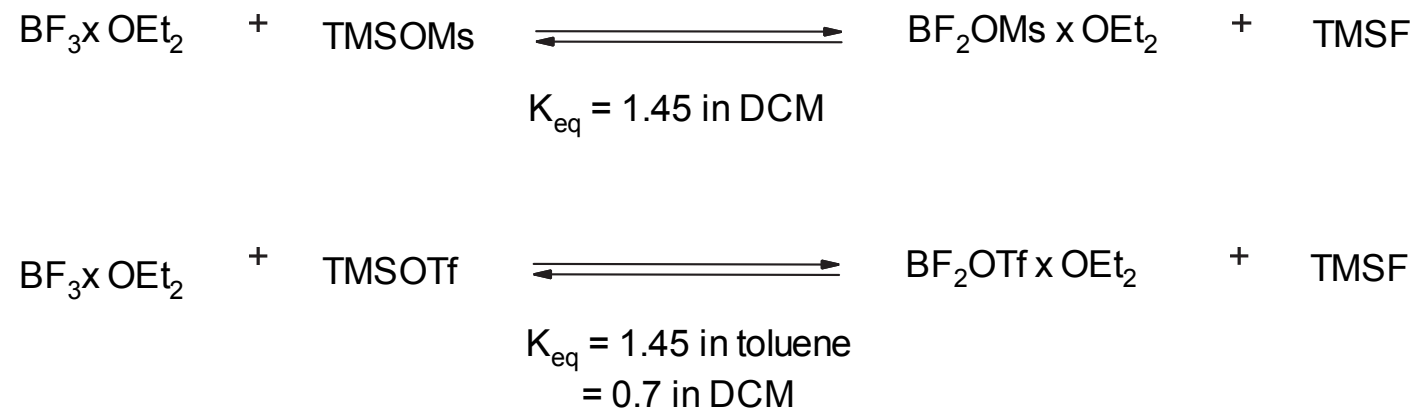

\section{Scheme 14}

Using the strongest Lewis acid $\mathrm{BF}_{2} \mathrm{OTf}_{\text {OEt }}$ the authors completed reduction of the series of esters 44 to ethers 45 (Table 1). In most cases, however, selectivity was low; formation of larger 
quantities of alcohols 46 and smaller quantities of silylesters 47 were observed. Presently, this method seems limited to relatively simple aliphatic esters, and requires optimization of reaction conditions in view of the high reactivity of $\mathrm{BF}_{2} \mathrm{OTf} . \mathrm{OEt}_{2}$ complex.

Table 1. Reduction of esters with varying steric crowding

\begin{tabular}{|c|c|c|c|c|c|c|c|}
\hline & \multirow[b]{2}{*}{4} & \multicolumn{2}{|c|}{$\begin{array}{c}\mathrm{BF}_{3} \times \mathrm{OEt}_{2}, \mathrm{TMSOTf} \\
\text { toluene, } \mathrm{Et}_{3} \mathrm{SiH}\end{array}$} & $\mathrm{R}^{1}$ & \multirow[b]{2}{*}{ 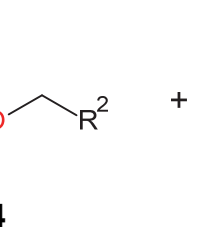 } & \multirow{2}{*}{$\begin{array}{c}\mathrm{R}-\mathrm{OH} \\
\mathbf{4}\end{array}$} & \multirow[t]{2}{*}{$\mathrm{R}^{2}-\mathrm{OSiEt}_{3}$} \\
\hline & & & & 4 & & & \\
\hline Entry & $\mathrm{R}^{1}$ & $\mathrm{R}^{2}$ & Time $(\mathrm{h})$ & Conditions & Ether $(\%)$ & Alcohol (\%) & Silylether (\%) \\
\hline \multirow[t]{2}{*}{1} & $\mathrm{Ph}\left(\mathrm{CH}_{2}\right)_{3}$ & $\mathrm{Me}$ & 28 & A & 50 & 41 & 8 \\
\hline & & & & B & 62 & 36 & 0 \\
\hline \multirow[t]{2}{*}{2} & $\mathrm{Ph}\left(\mathrm{CH}_{2}\right)_{3}$ & i-Pr & 72 & A & 47 & 44 & 6 \\
\hline & & & & $\mathrm{B}$ & 58 & 40 & 0 \\
\hline \multirow[t]{2}{*}{3} & $\mathrm{Ph}\left(\mathrm{CH}_{2}\right)_{3}$ & $\mathrm{t}-\mathrm{Bu}$ & 120 & A & 47 & 47 & 4 \\
\hline & & & & $\mathrm{B}$ & 57 & 42 & 0 \\
\hline \multirow[t]{2}{*}{4} & $\mathrm{Ph}\left(\mathrm{CH}_{2}\right)_{3}$ & $\mathrm{H}$ & 24 & $\mathrm{~A}$ & 46 & 48 & 3 \\
\hline & & & & B & 62 & 36 & 0 \\
\hline \multirow[t]{2}{*}{5} & $\mathrm{Me}$ & $\mathrm{Ph}\left(\mathrm{CH}_{2}\right)_{2}$ & 48 & A & 52 & - & - \\
\hline & & & & B & 70 & - & - \\
\hline \multirow[t]{2}{*}{6} & $\mathrm{Ph}\left(\mathrm{CH}_{2}\right)_{3}$ & $\mathrm{Ph}\left(\mathrm{CH}_{2}\right)_{2}$ & 72 & A & 67 & 20 & 9 \\
\hline & & & & B & 71 & 26 & 0 \\
\hline
\end{tabular}

Reaction conditions: $\mathrm{A}=$ TMSOTf (6 equiv.), $\mathrm{BF}_{3} . \mathrm{OEt}_{2}$ (1.2 equiv.); $\mathrm{B}=\operatorname{TMSOTf}$ (1.2 equiv.), $\mathrm{BF}_{3} . \mathrm{OEt}_{2}$ (1.8 equiv.), reduced pressure $(40 \mathrm{mmHg}), 2 \mathrm{~h}$.

\subsection{Reductions by silanes and Lewis acids}

Corriu and co-workers ${ }^{65}$ reported in an early paper on hydrosilylation of esters by trialkoxysilanes, in the presence of $\mathrm{CsF}$ and in the absence of solvent, a method to afford alcohols in $65-90 \%$ yield.

Trichlorosilane, activated by photochemical excitation, has been shown to reduce esters to ethers. $^{66-68}$ For the series of alkyl esters reduction to ethers in $80-100 \%$ yield is reported. In analogy to addition of silanes to the carbonyl group, the mechanism of reduction was proposed (Scheme 15). ${ }^{68}$

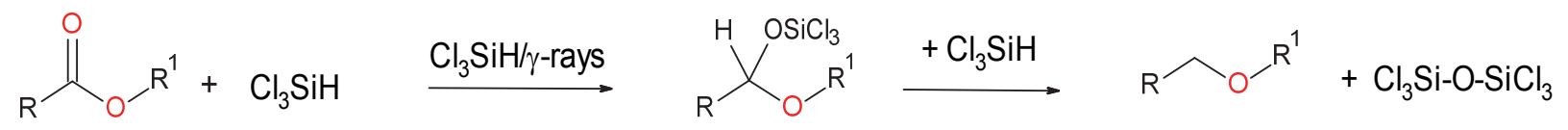

\section{Scheme 15}


Important modification of this procedure, which requires $\gamma$-rays induction, was achieved by the combined use of $\mathrm{TiCl}_{4}$ and TMSOMs. ${ }^{69}$ In Table 2 results are shown for the selected group of esters 48 to ethers 49. One observes the use of a molar excess of $\mathrm{Et}_{3} \mathrm{SiH}$ and TMSOTf, and 50\% mol excess of $\mathrm{TiCl}_{4}$, presenting a less attractive aspect of this method.

Table 2. Reduction of ester 1a to ether $\mathbf{2 a}$ with $\mathrm{Et}_{3} \mathrm{SiH}$ in the presence of $\mathrm{TiCl}_{4}$

\begin{tabular}{cccccccc}
\hline Entry & $\begin{array}{c}\mathrm{Et}_{3} \mathrm{SiH} \\
(\mathrm{mol})\end{array}$ & $\begin{array}{c}\mathrm{TiCl}_{4} \\
(\mathrm{~mol})\end{array}$ & $\begin{array}{c}\text { TMSOTf } \\
(\mathrm{mol})\end{array}$ & $\begin{array}{c}\mathrm{AgOTf} \\
(\mathrm{mol})\end{array}$ & $\begin{array}{c}\mathrm{TMSCl} \\
(\mathrm{mol})\end{array}$ & \multicolumn{2}{c}{ Yield (\%) } \\
\hline 1 & 5.0 & 3.0 & - & - & - & 27 & 61 \\
2 & 5.0 & 1.5 & 0.5 & - & - & 35 & 54 \\
3 & 5.0 & 1.5 & 1.5 & - & - & 65 & 14 \\
4 & 5.0 & 1.5 & 3.0 & - & - & 81 & - \\
5 & 5.0 & 1.5 & 3.0 & - & - & 58 & - \\
6 & 5.0 & - & 3.0 & - & - & - & 88 \\
7 & 5.0 & 1.5 & - & 3.0 & - & 63 & - \\
8 & 5.0 & 1.5 & - & 3.0 & 3.0 & 76 & - \\
\hline
\end{tabular}

Additionally, in this reaction the yield of ethers does not exceed $80 \%$, and larger quantities of non-reacted ester are found.

Hydrosilylation reactions were initially not catalyzed by transition metals and led to primalcohols. ${ }^{70-73}$ Catalyzed hydrosilylations giving prim- alcohols ${ }^{74-77}$ have also been reported by Cutler and co-workers ${ }^{78}$ who reported first hydrosilylation of esters to ethers (Scheme 16).<smiles>[R]OC([R])=O</smiles>

50<smiles>[R]OC([R])O[InH]</smiles>

silyl acetals<smiles>[R]CO[R]</smiles>

51

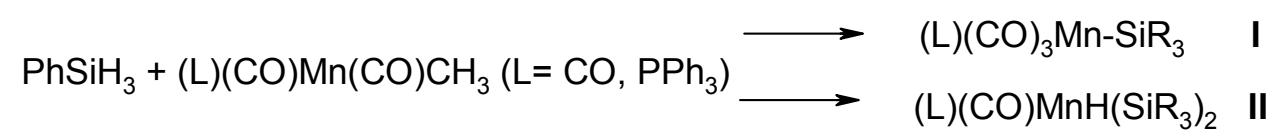

$\left(\mathrm{PPh}_{3}\right)(\mathrm{CO}) \mathrm{MnC}(\mathrm{O}) \mathrm{CH}_{3}$ catalyzed hydrosilylation by $\mathrm{PhSiH}_{3}$

$\begin{array}{lcc}\text { Ester } & \text { Conversion of estera, min } & \text { Ether, NMR yield\% } \\ \text { Me-COOMe, Et } & 15 & 85 \\ \text { Me-COOi-Pr } & 30 & 95 \\ \text { Me }\left(\mathrm{CH}_{2}\right)_{4} \text {-COOEt } & 30 & 81 \\ \text { Cyclohexyl-COOMe } & 25 & 89\end{array}$

\section{Scheme 16}


This reaction is characterized by formation of precatalytic complexes I and II and their intervention into formation of silylacetals, which in the second step undergo hydrogenolysis. This reaction is very fast and the yields are $80-95 \%$. A problem remains in preparation of the catalyst which is preferentially available by photochemical activation then by thermal reaction.

Nagashima and co-workers ${ }^{79}$ have introduced in this reaction a new catalytic system consisting of a trirhuteniumcarbonyl cluster and aromatic ligands as bridges, structures $\mathbf{5 2}$ and $\mathbf{5 3}$ (Scheme 17).

Preparation of catalytic complexes $\mathbf{5 2}$ and $\mathbf{5 3}$ was reported previously ${ }^{80}$ and monitoring of reaction by NMR has shown intermediary formation of silyl acetals, analogous to that shown in the Scheme 16. Complex 53 proved completely selective in formation of ether 56, at room temperature and in a short reaction time. In the same paper the authors have studied selectivity of 53 in reduction of some other esters and lactones to ethers. ${ }^{79}$ It turned out that reduction of lactones to cyclic ethers proceeds with significantly higher selectivity then for acyclic ethers, and that the later can be reduced with higher selectivity in dioxane then in tetrahydropyrane.

It was also observed that the trirhutenium complex 52 in the presence of hydrosilane can selectively catalyze the split of the $\mathrm{C}-\mathrm{O}$ bond of the $\mathrm{O}-\mathrm{t} \mathrm{Bu}$ group in carbamates, carbonates, esters and ethers. ${ }^{81}$ Due to its efficiency and selectivity this reaction is suggested as a new deprotection method for the O- $t \mathrm{Bu}$ group.

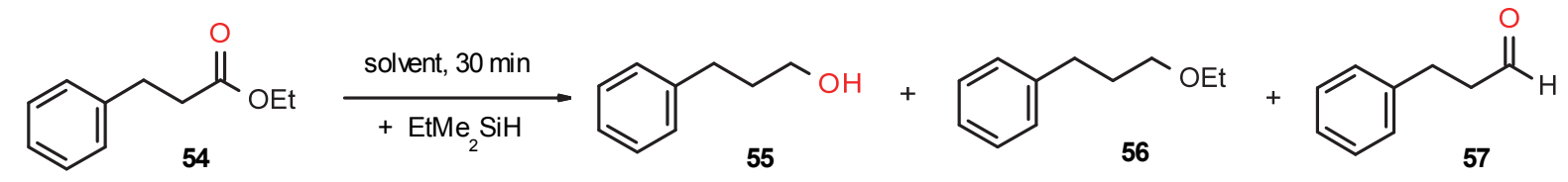

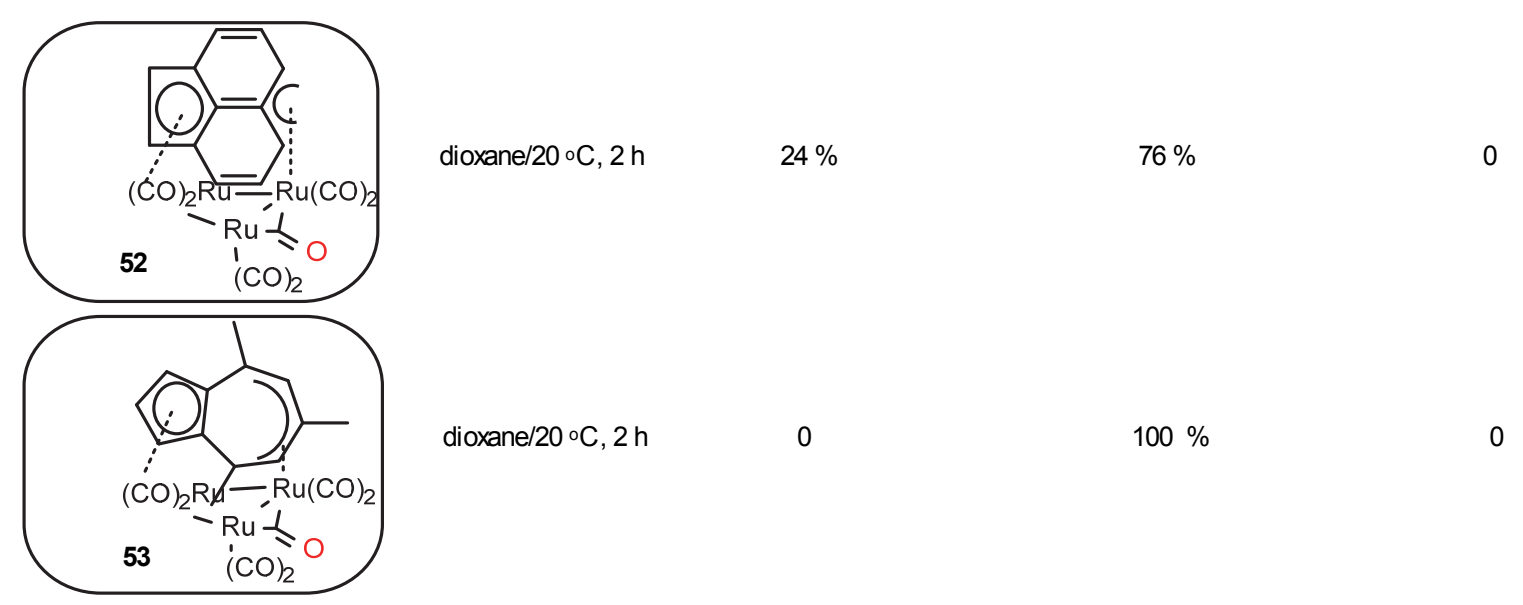

\section{Scheme 17}

Reductive alkylation of aldehydes to ethers is related to ester reduction, since it uses trialkylsilanes in the presence of a catalytic quantity of Fe (III) ions and trimethylsilyl ethers as alkylating agents (Scheme 18). ${ }^{82}$ 


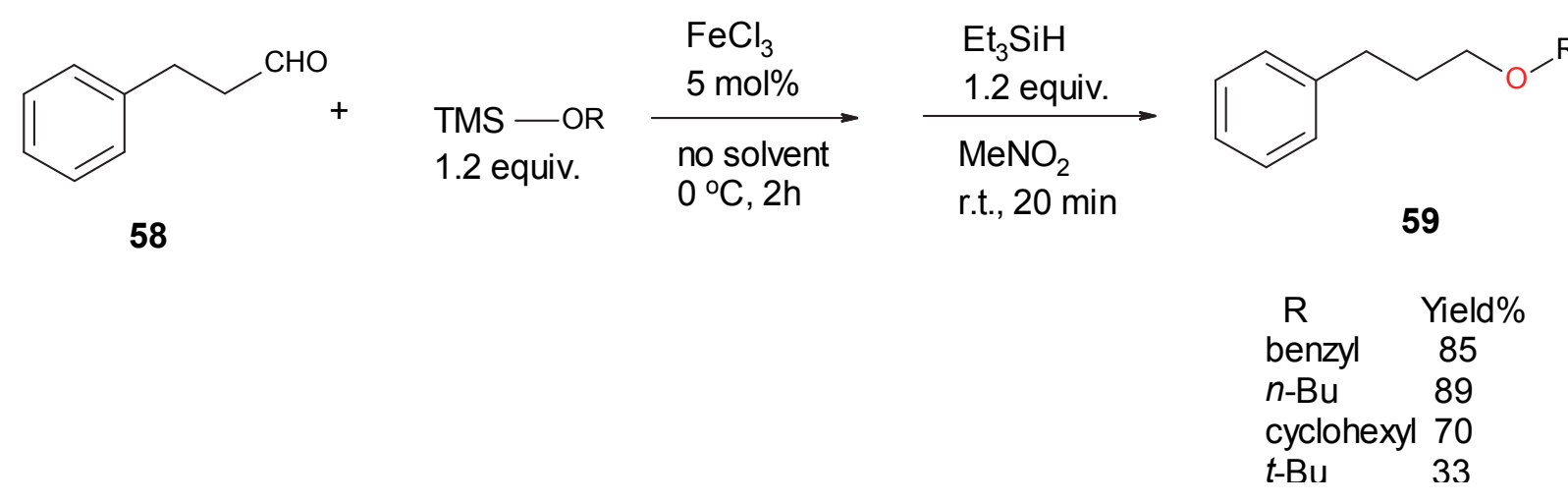

\section{Scheme 18}

By this two-step one-pot reductive alkylation aromatic aldehydes can also be alkylated, though the yields are somewhat lower. The obvious advantages of the method are the cheap catalyst and short reaction time under mild conditions. A development of this method involves the application of $\mathrm{InBr}_{3} / \mathrm{Et}_{3} \mathrm{SiH}$ as the catalytic system. ${ }^{83}$ Selection of the solvents and optimization of the reaction conditions is presented (Table 3).

Table 3. Optimization of the reaction conditions for reduction of $\mathbf{6 0}$ to $\mathbf{6 1}$

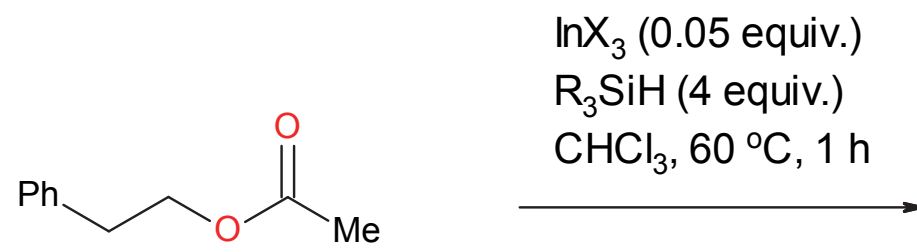

60 ( 1 equiv.)

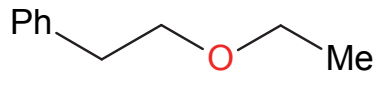

61

\begin{tabular}{ccccc}
\hline Entry & $\mathrm{InX}_{3}$ & $\mathrm{R}_{3} \mathrm{SiH}$ & Solvent & Yield (\%) \\
\hline 1 & $\mathrm{InBr}_{3}$ & $\mathrm{Et}_{3} \mathrm{SiH}$ & $\mathrm{CHCl}_{3}$ & 99 \\
2 & $\mathrm{InBr}_{3}$ & $\mathrm{Et}_{3} \mathrm{SiH}$ & $\mathrm{PhH}$ & 90 \\
3 & $\mathrm{InBr}_{3}$ & $\mathrm{Et}_{3} \mathrm{SiH}$ & $\mathrm{PhMe}$ & 85 \\
4 & $\mathrm{InBr}_{3}$ & $\mathrm{Et}_{3} \mathrm{SiH}$ & $\mathrm{THF}$ & $\mathrm{NR}$ \\
5 & $\mathrm{InBr}_{3}$ & $\mathrm{Et}_{3} \mathrm{SiH}$ & $\mathrm{MeCN}$ & 4 \\
6 & $\mathrm{InBr}_{3}$ & $\mathrm{Et}_{3} \mathrm{SiH}$ & $\mathrm{CHCl}_{3}$ & $\mathrm{NR}$ \\
7 & ${\mathrm{In}(\mathrm{OTf})_{3}}$ & $\mathrm{Et}_{3} \mathrm{SiH}$ & $\mathrm{CHCl}_{3}$ & Trace \\
8 & ${\mathrm{IN}(\mathrm{OAc})_{3}} \mathrm{Et}_{3} \mathrm{SiH}$ & $\mathrm{CHCl}_{3}$ & $\mathrm{NR}$ \\
9 & $\mathrm{InBr}_{3}$ & $\left(\mathrm{EtO}_{3} \mathrm{SiH}\right.$ & $\mathrm{CHCl}_{3}$ & 10 \\
10 & $\mathrm{InBr}_{3}$ & $\mathrm{PhMe}_{2} \mathrm{SiH}$ & $\mathrm{CHCl}_{3}$ & 94 \\
\hline
\end{tabular}

$\mathrm{NR}=$ no reaction 
Chloroform was found to be the best solvent; benzene and toluene were nearly as good, whereas reaction in $\mathrm{THF}$ and $\mathrm{MeCN}$ did not proceed. When the reaction was attempted in the presence of $\mathrm{InCl}_{3}, \mathrm{In}(\mathrm{OAc})_{3}$ and $\mathrm{In}(\mathrm{OTf})_{3}$ no product was observed. Best results were obtained with 0.05 equiv. of $\mathrm{InBr}_{3}$ and 4 equiv. of $\mathrm{Et}_{3} \mathrm{SiH}$ in chloroform. The authors suggested the mechanism shown below (Scheme 19).

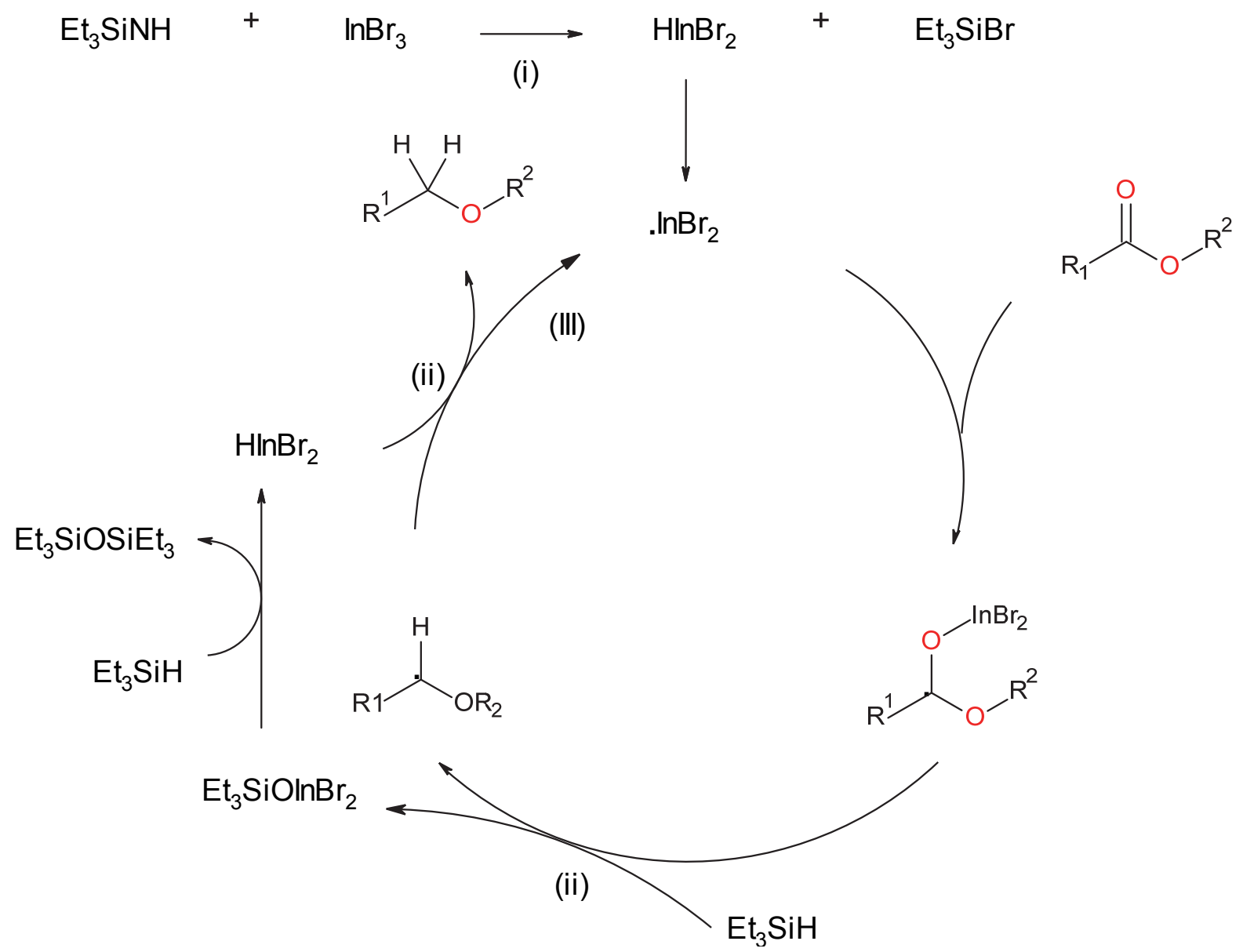

\section{Scheme 19}

This process includes the following steps; (i) initial transmetalation between $\mathrm{InBr}_{3}$ and $\mathrm{Et}_{3} \mathrm{SiH}$, (ii) formation of a radical intermediate, consecutive split of the $\mathrm{H}$ atom from $\mathrm{Et}_{3} \mathrm{SiH}$ and formation of the radical ether product, (iii) and in the final step the indium radical species is regenerated.

In a following paperi ${ }^{84}$ the authors have applied this method to selected esters (Table 4). 
Table 4. Reduction of esters to ethers by $\mathrm{InBr}_{3} / \mathrm{Et}_{3} \mathrm{Si}$

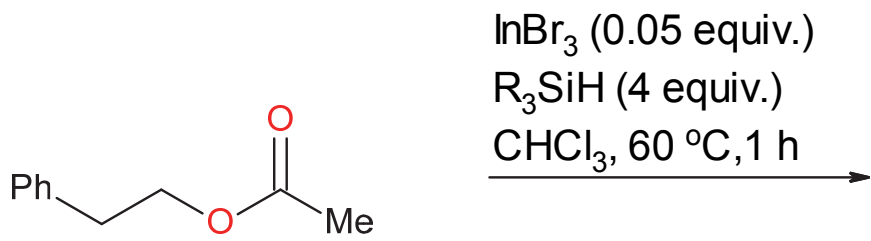

60

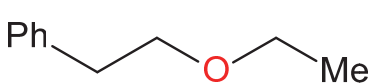

61

\begin{tabular}{|c|c|c|c|c|c|}
\hline Entry & Ester $\mathbf{6 0}$ & & & Ether $\mathbf{6 1}$ & Yield $(\%)$ \\
\hline 1 & & & & & 92 \\
\hline 2 & & & & & 69 \\
\hline 3 & ${ }_{2} \mathrm{C}_{6}$ & & & & 61 \\
\hline 4 & & & 4 & & 89 \\
\hline 5 & $\mathrm{R}=n$ & & 10 & $\mathrm{R}=r$ & 71 \\
\hline 6 & $\mathrm{R}=i$ & & 1 & $\mathrm{R}=$ & 71 \\
\hline 7 & $\mathrm{R}=t-$ & & 10 & $\mathrm{R}=t$ & 30 \\
\hline 8 & $\begin{array}{r}\mathrm{R}=\text { cyclo } \\
1 \mathrm{~h}\end{array}$ & & 10 & $\mathrm{R}=$ cycl & 53 \\
\hline 9 & & & 1 & & 89 \\
\hline 10 & & & 6 & ${ }_{4}^{-}-\mathrm{NO}_{2} \mathrm{C}_{6} \mathrm{~F}$ & 62 \\
\hline
\end{tabular}

The results demonstrate compatibility of the process with the presence of the nitro group, bromine atom and thiophene ring, and revealed that sterically crowded groups in the alcohol do not hinder the reduction. 5-And 6-membered lactones are reduced to cyclic ethers in high yields. The same authors ${ }^{85,86}$ reported on another aspect of catalytic deoxygenation of esters by $\mathrm{InBr}_{3} / \mathrm{R}_{3} \mathrm{SiH}$. In the first paper sequential preparation of symmetrical ethers has been accomplished (Scheme 20). ${ }^{85}$ 


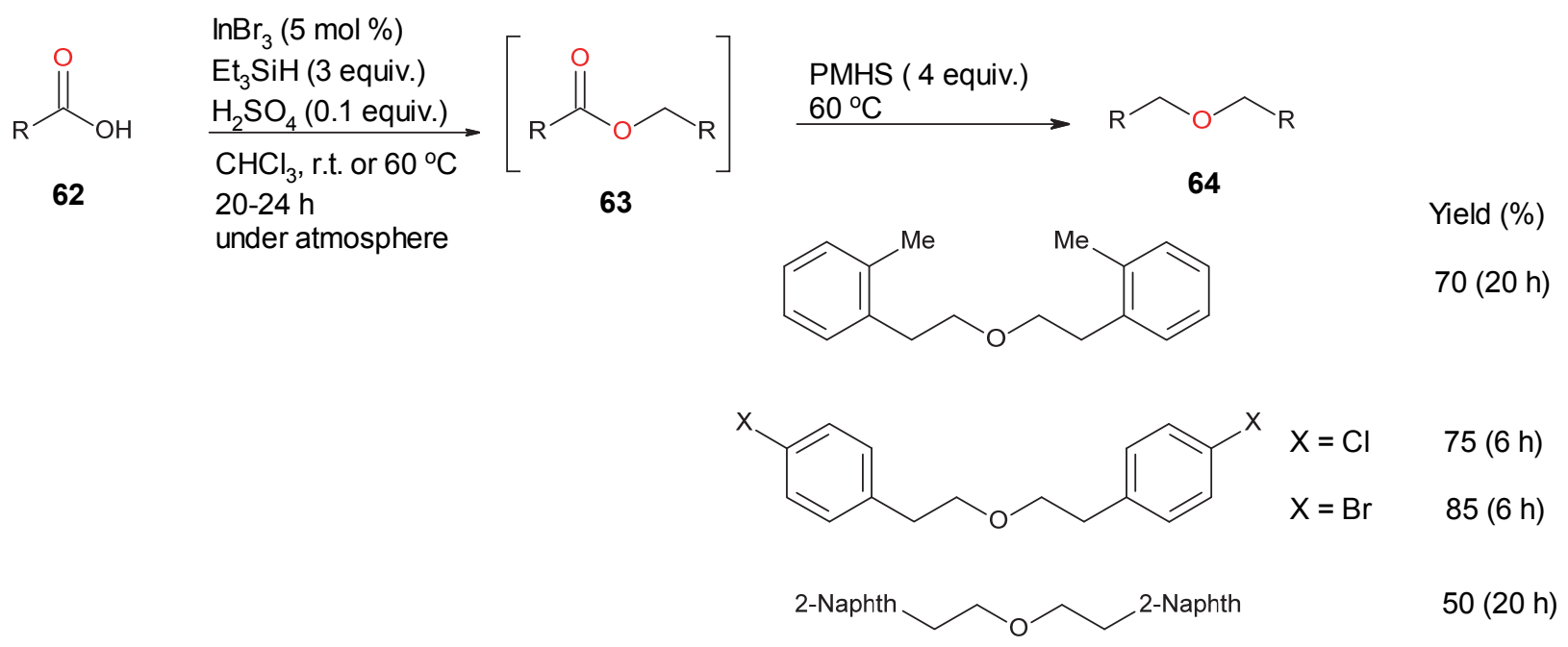

\section{Scheme 20}

Table 5. One-pot synthesis of ethers from various carboxylic acids and phenylethyl alcohol<smiles>[R]C(=O)O</smiles>

(1-2 equiv.)
1. $\operatorname{lnBr}_{3}(5$ mol. $\%)$

$\mathrm{PhMe}, 100^{\circ} \mathrm{C}, 20 \mathrm{~h}$

2. PMHS (10-20 equiv.) $100{ }^{\circ} \mathrm{C}, 8 \mathrm{~h}$

62

63

64

\begin{tabular}{|c|c|c|c|}
\hline Entry & Silane (equiv.) & Product & Yield (\%) \\
\hline 1 & 10 & & 82 \\
\hline 2 & 15 & & 91 \\
\hline 3 & 15 & & 45 \\
\hline 4 & 10 & & 92 \\
\hline 5 & 20 & & 58 \\
\hline 6 & 15 & & 48 \\
\hline 7 & 10 & & 71 \\
\hline
\end{tabular}


In the first step unprecedented reductive dimerization of two carboxylic acids $\mathbf{6 2}$ to produce ester derivatives 63 by combination of the catalyst involving $\operatorname{InBr}_{3}$ and sulfuric acid is achieved. A sequential conversion of the in-situ formed ester to symmetrical ethers was accomplished in the same pot by indium-catalyzed deoxygenation of the ester with a hydrosilane. ${ }^{86}$ In the second paper ${ }^{86}$ the authors have developed "a widely applicable and direct method" of etherification from carboxylic acid and an alcohol by indium-catalyzed deoxygenation of the transient esters to ethers 64. They also demonstrated remarkable tolerance of the catalytic system in the presence of several functional groups including alkenes, halogens, nitro group and hererocyclic unit, Table 5.

A plausible mechanism for the indium-catalyzed reductive deoxygenation of esters en route to ethers is presented in the Scheme 21. ${ }^{85}$

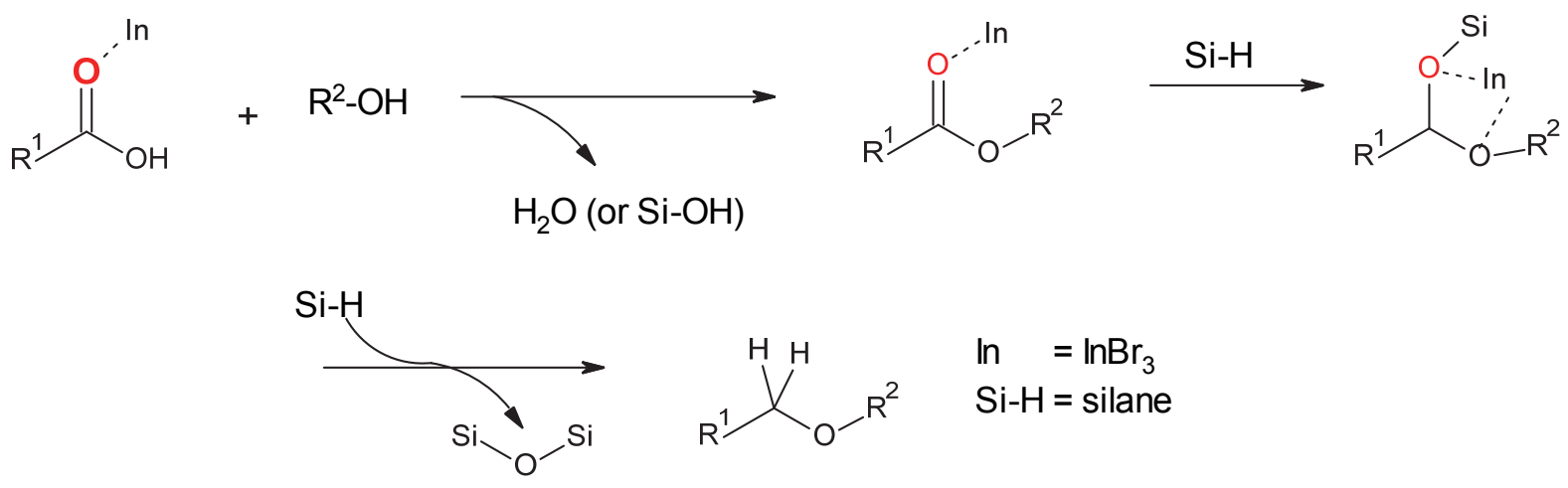

\section{Scheme 21}

According to this mechanism $\operatorname{InBr}_{3}$ has several roles, the first being to promote the condensation of a carboxylic acid and an alcohol and to subsequently activate the ester formed in situ to facilitate hydrosilylation by a silane. The silyl acetal thus generated is then again activated by $\mathrm{InBr}_{3}$ transforming the corresponding ether by the second hydrosilylation and desiloxylation.

\section{Conclusions}

Undoubtedly, development of new methods for the reduction of esters to ethers and further improvement of existing protocols are on the horizon. Understanding the mechanism of these particular reactions may have will certainly lead to a focused, rational improvement in the procedures. The evolution from exceptional transformation to useful reaction and /or synthetic method has followed the general evolution from rare to applicable synthetic methods. Although there is no single synthetic method which can be universally applied, ether functionality can now be synthesized by a wide range of available methods. Each method has its unique advantages and limitations, which must be carefully considered when choosing which method to use for a specific starting material. 


\section{Acknowledgment}

We thank Dr. Phil Dudfield and Dr. Gregory Bar for a critical reading of the manuscript. Ivan Grgicevic is acknowledged for his technical assistance.

\section{References}

1. Blanksby, S. J.; Ellison, G. B. "Bond Dissociation Energies of Organic Molecules" in Acc Chem. Res. 2003, 36, 255-263.

http://dx.doi.org/10.1021/ar020230d

2. Addis, D.; Das, S.; Junge, K.; Beller, M. Angew. Chem. Int. Ed. 2011, 50, 6004. http://dx.doi.org/10.1002/anie.201100145

3. Clarke, M. L. Catal. Sci. Technol. 2012, (2), 2418. http://dx.doi.org/10.1039/C2CY20601C

4. Igarashi M.; Mizuno R, Fuchikami, T. Tetraheron Lett. 2001, 42, 2149. http://dx.doi.org/10.1016/S0040-4039(01)00094-6

5. Cheng, C.; Brookhart, M. Angew. Chem. Int. Ed. 2012, 51, 9422. http://dx.doi.org/10.1002/anie.201205154

6. Li, H.; Misal Castro, L. C.; Zheng, J.; Roisnel, T.; Dorcet, V.; Sortais, J.-B.; Darcel, C. Angew. Chem. Int. Ed. 2013, 52, 8045.

http://dx.doi.org/10.1002/anie.201303003

7. March, J.; March's Advanced Organic Chemistry, Reaction, Mechanims and Structure, 6th ed.; Wiley\&Sons, New York, 2007, pp. 529.

8. Sawyer, J. S. Tetrahedron 2000, 56, 5045

http://dx.doi.org/10.1016/S0040-4020(00)00257-X

9. Frlan, R.; Kikelj, D. Synthesis 2006, 14, 2271. http://dx.doi.org/10.1055/s-2006-942440

10. Williamson, A.W. J. Chem. Soc. 1852, 4, 229. http://dx.doi.org/10.1039/QJ8520400229

11. Bugget,N. Comprehensive Organic Synthesis, Barton, D.; Ollis, W. D.; Eds.; Pergamon Oxford 2000, Vol. 1, 799.

12. March, J.; March's Advanced Organic Chemistry, Reaction, Mechanims and Structure, 5th ed.; Wiley\&Sons, New York. 2001, p. 477.

13. Callahan, F. M.; Anderson, G. W.; Paul, R.; Zimmerman, J. E. J. Am. Chem. Soc. 1963, 85, 201.

http://dx.doi.org/10.1021/ja00885a020

14. Kashman, Y. J. Org. Chem. 1972, 37, 912.

http://dx.doi.org/10.1021/jo00971a021

15. Torii, S.; Takagishi, S.; Inokuchi, T.; Okumoto, H. Bull. Chem. Soc. Jpn. 1987, (60), 775. http://dx.doi.org/10.1246/bcsj.60.775 
16. Sammers, P. G.; Thetford, D.; Voyle, M. J. Chem. Soc. Chem. Commun. 1987, 1373. http://dx.doi.org/10.1039/C39870001373

17. Bagnell, L; Cablewski, T.; Strauss, C. R. Chem. Commun. 1999, 283. http://dx.doi.org/10.1039/A808980I

18. Ullmann F.; Sponagel P. Chem. Ber. 1905, 38, 2211. http://dx.doi.org/10.1002/cber.190503802176

19. Ullmann, F. Bielecki, J. Chem. Ber. 1901, 34, 2174. http://dx.doi.org/10.1002/cber.190103402141

20. Ullmann, F. Chem. Ber. 1903, 36, 2382. http://dx.doi.org/10.1002/cber.190303602174

21. Benaskar, F.; Patil, N. G.; Engels, V.; Rebrov, E. V.; Meuldijk, J.; Hulshof, L. A.; Hessel, V.; Wheatley, A. E. H.; Schouten, J. C. Chem. Eng. J. 2012, 207-208, 426. http://dx.doi.org/10.1016/j.cej.2012.06.147

22. Babu, S. G.; Karvembu, R. Tetrahedron Lett. 2013, 541677. http://dx.doi.org/10.1016/j.tetlet.2013.01.063

23. Mitsunobu, O.; Comprehensive Organic Synthesis, Trost, B. M.; Fleming, I. Eds.; Pergamon New York, 1991, Vol. 6.

24. Kumara Swamy, K. C.; Bhuvan Kumar, N.N.; Balaraman E.; Pavan Kumar, K.V.P. Chem. Rev. 2009, 109, 2551. http://dx.doi.org/10.1021/cr800278z

25. Shi, J.; Hughes, D. L.; McNamara, J. M. Tetrahedron Lett. 2003, 44, 3609. http://dx.doi.org/10.1016/S0040-4039(03)00728-7

26. Guanti, G.; Banfi, L.; Basso, A.; Bevilacqua, E.; Bindanza, L.; Riva, R. Tetrahedron: Asymmetry 2004, 15, 2889. http://dx.doi.org/10.1016/j.tetasy.2004.07.040

27. Dandapani S.; Curran, D. P. Chem. Eur. J. 2004, 10, 3130. http://dx.doi.org/10.1002/chem.200400363

28. Zumpe, F. L.; Kazmaier, U. Synthesis 1999, 1785. http://dx.doi.org/10.1055/s-1999-3598

29. Muzart, J. Tetrahedron 2005, 61, 5955. http://dx.doi.org/10.1016/j.tet.2005.04.002

30. Hosokawa, T.; Shinohara, T.; Ooka, Y.; Murahashi, S.-I. Chem. Lett. 1989, 2001. http://dx.doi.org/10.1246/c1.1989.2001

31. Miller, K. J.; Kitagawa, T. T.; Abu-Omar, M. M. Organometallics 2001, 20, 4403. http://dx.doi.org/10.1021/om0103097

32. Satoh, T.; Ikeda, M.; Miura, M.; Nomura, M. J. Org. Chem. 1997, 62, 4877. http://dx.doi.org/10.1021/jo970534r

33. Palej Jakopović, I.; Kragol, G.; Forrest, A. K.; Frydrych, C. S. V; Štimac, V.; Kapić ,S.; Matanović' Škugor, M.; Ilijaš, M.; Čipčić Paljetak, H.; Jelić, D.; Holmes, D. J.; Hickey, D. 
M. B.; Verbanac, D.; Eraković Haber, V.; Alihodžić , S. Bioorg. Med. Chem. 2010, 18, 6578-6588.

http://dx.doi.org/10.1016/j.bmc.2010.07.007

34. Kapić, S.; Č ipčić Paljetak, H.; Palej Jakopović, I.; Fajdetić, A.; Ilijaš, M.; Štimac, V.; Brajša, K.; Holmes, D. J.; Berge J.; Alihodžić, S. Bioorg. Med. Chem. 2011, 19, 7281-7298.

http://dx.doi.org/10.1016/j.bmc.2011.07.010

35. Burgos, C. H.; Barder, T. E.; Huang, X.; Buchwald, S. L. Angew. Chem. Int. Ed. 2006, 45, 4321.

http://dx.doi.org/10.1002/anie.200601253

36. (a) Wolfe, J. P.; Wagaw, S.; Marcoux, J.-F.; Buchwald, S. L. Acc. Chem. Res. 1998, (31), 805 .

http://dx.doi.org/10.1021/ar9600650

(b) Hartwig, J. F. Acc. Chem. Res. 1998, 31, 852.

http://dx.doi.org/10.1021/ar970282g

37. Dehli, J. R.; Legros, J.; Bolm, C. Chem. Commun. 2005, 973.

http://dx.doi.org/10.1039/B415954C

38. Olivera R.; SanMartin R.; Churruca, F.; Dominguez, E. J. Org. Chem. 2002, 67, 7215. http://dx.doi.org/10.1021/jo025767j

39. Lipschutz, H. B.; Nihan, D. M.; Vinogradova E.; Taft, B. R.; Bošković, Ž. V. Org. Letters 2008, 10, 4279.

http://dx.doi.org/10.1021/o1801676u

40. Akkoca, M.; Gurbuza, N.; Cetinkayab, E.; Ozdemir, I. Synlett 2008, 1781. http://dx.doi.org/10.1055/s-2008-1078548

41. Shi, Y.-J.; Hughes, D. L.; McNamara, J. M.; Tetrahedron Lett. 2003, 44, 3609. http://dx.doi.org/10.1016/S0040-4039(03)00728-7

42. Shintou, T.; Mukayama, T. Chem. Lett. 2003, 32, 984.

http://dx.doi.org/10.1246/cl.2003.984

Ibid. 2003, 32, 1100.

http://dx.doi.org/10.1246/c1.2003.1100

43. Shintou, T.; Mukaiyama, T. J. Am. Chem. Soc. 2004, 126, 7359.

http://dx.doi.org/10.1021/ja0487877

44. Ooi, T.; Ichikawa, H.; Itagaki, Y.; Maruoka, K. Heterocycles, 2000, 52, 575. http://dx.doi.org/10.3987/COM-99-S99

45. Bethmont, V.; Fache F.; Lemaire, M. Tetrahedron Lett. 1995, 36, 4235. http://dx.doi.org/10.1016/0040-4039(95)00730-Z

46. Hassan, J.; Sevignon, M.; Gozzi, C.; Schulz, E.; Lemaire, M. Chem. Rev. 2002, 102, 1359. http://dx.doi.org/10.1021/cr000664r

47. Fujii, Y.; Furugaki, H.; Kita K.; Morimoto, H.; Uno, M.; Kajihara, Y. U.S. Pat 6011071 (2000), Prior. Appl. Jpn. Patent JP 95118309, 17 May, 1995. Chem. Abstr. 1997, 126, 61873. 48. Fujii ,Y.; Furukaga, H.; Tamura, E.; Yano, S.; Kita, K. Bull. Chem. Soc. Jpn. 2005, 78, 456. 
http://dx.doi.org/10.1246/bcsj.78.456

49. Pedersen, B. S.; Shheibye, S.; Clausen, K.; Lawson, S. O. Bull. Soc. Chim. Belg. 1978, 87, 223.

50. Baxter, S. L.; Bradshaw, J. S. J. Org. Chem. 1981, 46, 831. http://dx.doi.org/10.1021/jo00317a045

51. Barrett, A. G. M.; Lee, A. C. J. Org. Chem. 1992, 57, 2818. http://dx.doi.org/10.1021/jo00036a012

52. Nicolaou, K. C.; McGarry, D. G.; Somers, P. K.; Kim, B. H.; Ogilvie, W. W.; Yiannikouros, G.; Prasad, C. V. C.; Veale, C. A.; Hark, R. J. Am. Chem. Soc. 1990, 112, 6263. http://dx.doi.org/10.1021/ja00173a013

53. Kraus, G. A. Frazier, K. A.; Roth, B. C.; Taschner, M. J.; Neunschwander, K. J. Org. Chem. 1981, 46, 2417. http://dx.doi.org/10.1021/jo00324a050

54. Maione, A. M.; Torrini, J. Chemistry \& Industry 1975, 19, 839-40.

55. Pettit, G. R.; Kasturi, T. R. J. Org. Chem. 1960, 25, 875. http://dx.doi.org/10.1021/jo01075a635

56. Pettit, G. R.; Kasturi, T. R. J. Org. Chem. 1961, 26, 4553. http://dx.doi.org/10.1021/jo01069a086

57. Pettit, G. R.; Kasturi, T. R. J. Org. Chem. 1962, 27, 2127. http://dx.doi.org/10.1021/jo01053a054

58. Dias, J. R.; Pettit, G. R. J. Org. Chem. 1971, 36, 3485. http://dx.doi.org/10.1021/jo00822a003

59. Pettit, G. R.; Green, B.; Kasturi, T. R.; Ghatak, U. R. Tetrahedron 1962, 18, 953. http://dx.doi.org/10.1016/S0040-4020(01)92749-8

60. Morra, N. A.; Pagenkopf, B. L. Synthesis 2008, 511. http://dx.doi.org/10.1055/s-2008-1032141

61. Snieder, B. B.; in Comprehensive Organic Chemistry, Trost, B. M.; Fleming, I., Pergamon Press. Oxford 1991, Vol. 2, Chapter 2.1., 527.

62. Konig, K., Neumann, W. P. Tetrahedron Lett. 1967, 493-498. http://dx.doi.org/10.1016/S0040-4039(00)90536-7

63. Pindur, U.; Lutz, G.; Otto, C. Chem. Rev. 1993, 93, 741.

64. http://dx.doi.org/10.1021/cr00018a006

65. Carreira, E. M. in Modern Carbonyl Chemistry, Otera J., Ed.; Wiley. Weinheim 2000, Chapter 8.

66. Boyer, J.; Corriu, R. J.; Perz, R.; Poirier, M.; Reye, M. Synthesis 1981, 558. http://dx.doi.org/10.1055/s-1981-29527

67. Tsurugi, J.; Nakao, R.; Fukumoto, T. J. Am. Chem. Soc. 1969, 91, 4587. http://dx.doi.org/10.1021/ja01044a067

68. Baldwin, S.; Hant, S. A. J. Org. Chem. 1975, 40, 3885. http://dx.doi.org/10.1021/jo00914a016 
69. Calas, R.; Frainet, E.; Bonastre, J. Compt. Rend. 1960, 251, 2987.

http://dx.doi.org/10.1007/978-1-4684-2142-2_23

70. Yato, M.; Homma, K.; Ishida, A. Tetrahedron 2001, 57, 5353.

http://dx.doi.org/10.1016/S0040-4020(01)00420-3

71. Calas, R. Pure Appl. Chem. 1966, 13, 61 http://dx.doi.org/10.1351/pac196613010061

72. Chuit, C.; Corriu, R. J. P.; Perz, R.; Reye, C. Synthesis 1982, 981. http://dx.doi.org/10.1055/s-1982-30035

73. Corriu, R. J. P.; Perz, R.; Reye, M. Tetrahedron 1983, 39, 999. http://dx.doi.org/10.1016/S0040-4020(01)88599-9

74. Benkeser, R. A.; Ehler, D. F. J. Org. Chem. 1973, 38, 3660. http://dx.doi.org/10.1021/jo00960a062

75. Berk, S. C.; Kreutzer, K. A.; Buchwald, S. L. J. Am. Chem. Soc. 1991, 113, 5093. http://dx.doi.org/10.1021/ja00013a074

76. Berk, S. C.; Buchwald, S. L. J. Org. Chem. 1992, 57, 3751. http://dx.doi.org/10.1021/jo00040a001

77. Barr, K. J.; Berk, S. C.; Buchwald, S. L. J. Org. Chem. 1994, 59, 4323. http://dx.doi.org/10.1021/jo00094a056

78. Bower, S.; Kristina, K. A.; Buchwald, S. L. Angew. Chem. Int. Ed. 1996, 35, 1515. http://dx.doi.org/10.1002/anie.199615151

79. Mao, Z.; Gregg, B. T.; Cutler, A. R. J. Am. Chem. Soc. 1995, 117, 10139. http://dx.doi.org/10.1021/ja00145a036

80. Matsubara, K.; Iura, T.; Maki, T.; Nagashima, H. J. Org. Chem. 2002, 67, 4985. http://dx.doi.org/10.1021/jo025726n

81. Nagashima, H.; Suzuki, A.; Iura, T.; Ruy, K.; Matsubara, K. Organometallics 2000, 19, 3579 . http://dx.doi.org/10.1021/om0003887

82. Hanada, S.; Yuasa, A.; Kuriowa, H.; Motoyama, Y.; Nagashima, H. Eur. J. Org. Chem. 2010, 6, 1021. http://dx.doi.org/10.1002/ejoc.200901279

83. Iwanami, K.; Seo, H.; Oriyama, T. Synthesis 2005, 183. http://dx.doi.org/10.1055/s-2004-834942

84. Sakai, N.; Moriya, T.; Konakahara, T. J. Org. Chem. 2007, 72, 5920. http://dx.doi.org/doi/pdfplus/10.1021/jo070814z

85. Sakai, N.; Moriya, T.; Fujii, K.; Konakahara, T. Synthesis 2008, 3533. http://dx.doi.org/10.1055/s-0028-1083191

86. Sakai, N.; Usui, Y.; Ikeda, R.; Konakahara, T. Adv. Synth. Catal. 2011, (353), 3397. http://dx.doi.org/10.1002/adsc.201100524

87. Sakai, N.; Usui, Y.; Moriya, T.; Ikeda, R.; Konakahara, T. Eur. J. Org. Chem. 2012, 4603. http://dx.doi.org/10.1002/ejoc.201200552 


\section{Authors Biographies}

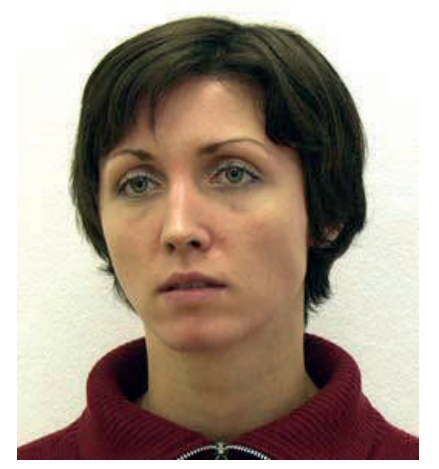

Ivana Palej Jakopović, completed her PhD degree in 2011 under the supervision of Kata Majerski, Prof. and Sulejman Alihodžić, focused on the discovery of new macrolide antibiotics. She started her industrial career in PLIVA Research Institute and for several years she has been working in the field of anti-inflammatory drugs in GSK research Centre Zagreb. Currently she is working in the Scale up group in Fidelta Ltd. She is an author/co-author of seven original scientific articles published in journals quoted by $\mathrm{CC}$ and six patent applications.

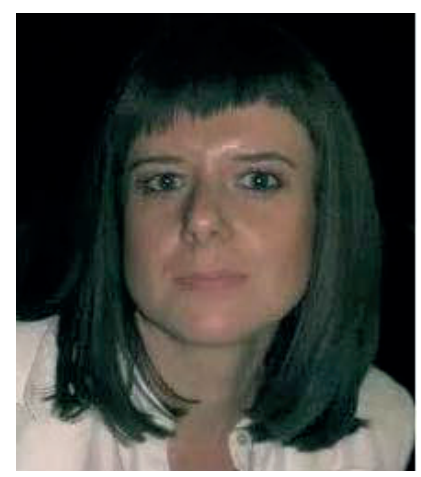

Samra Kapić completed her Ph.D. degree in 2010 under the supervision of Prof. Vitomir Šunjić and Dr Sulejman Alihodžić, working on the discovery of new macrolide antibiotics. She started working in pharmaceutical industry in 2002 as a Synthetic Chemist at PLIVA Research Institute, since 2006 she has been working as a Senior scientist - Medicinal chemist in GSK research centre Zagreb which is now Fidelta Ltd. in the field of anti-infectives and anti-inflammation. She is an author/co-author of seven original scientific articles published in journals quoted by $\mathrm{CC}$ and three patent applications. 


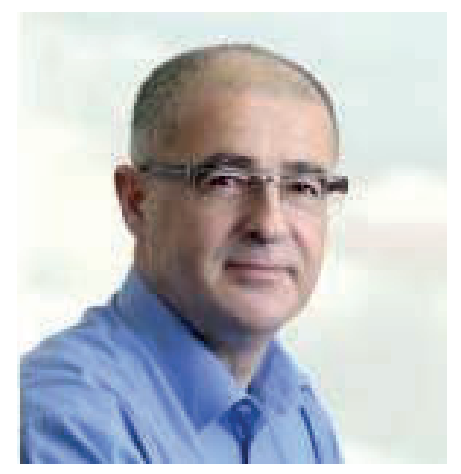

Sulejman Alihodžić completed his M.Sc. and Ph.D. degrees in 1992 and 1995, respectively, in Organic Chemistry under the supervision of Prof. Mladen Žinić at Ruđer Bošković Institute in Zagreb. From 1996 to 1998 he was a Robert A. Welch Post-doctoral Fellow at the University of North Texas where he worked with Prof. Alan P. Marchand in the area of high energy cages, aza- and diaza-crown ethers and kalixarenes. He started his industrial carrier in 1998 working in the pharmaceutical and biotech companies PLIVA, GlaxoSmithKline and Galapagos holding several leading positions including a Head of Chemistry (GSK) Zagreb. His work, focused mainly on anti-infective and anti-inflammatory research has contributed to the progression of several drug discovery projects. This is complemented by his extensive experience in the scaleup and physico-chemical profiling of NCEs. S.Alihodžić is author or coauthor of over 45 scientific papers and has applied for over 25 patents.

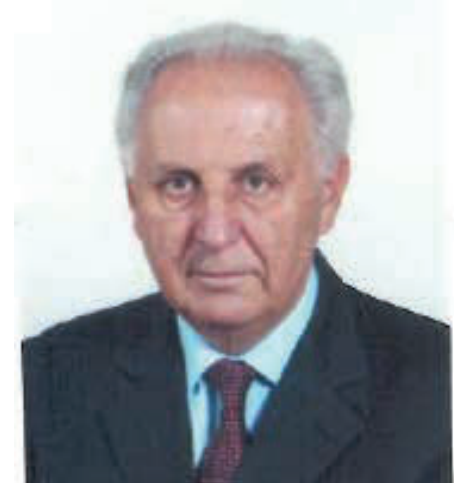

Vitomir Šunjić graduated in chemistry in 1963, and completed his Ph.D. in 1969 at the University of Zagreb. He spent his postdoctoral with Prof. Vlado Prelog in 1969-1970 at ETH, Zurich. After four years at the Institute of Chemistry, University of Zagreb he joined Compagnia di Ricerca Chimica (Udine, Italy) from 1975-1982. Then he was elected as senior scientist at Rudjer Bošković institute in Zagreb where he was active from 1982-2003, founded in 1988 Laboratory for Stereoselective Catalysis and Biocatalysis (CATBIO), and headed Department of Chemistry from1998-2003. From 1988 he was appointed professor of organic chemistry at Faculty of Mathematics and Natural Sciences, University of Zagreb. From 2003-2008 he joined PLIVA research institute. V. Šunjić is author or coauthor of over 230 papers, three books, and has applied for over 60 patents. In the period 1996-2002 he was elected member of ESOC 
Committee, and from 2001-2003 acted as the President of this Committee. He was awarded in 1990 by National price for research in chemistry, and in 1996 by the National Academy price for research in organic chemistry. From 2012 he is elected member of Croatian Academy of Sciences and Arts.

\section{Graphical Abstract}

